\title{
Repression of ci-D in posterior compartments of Drosophila by engrailed
}

\author{
Suzanne Eaton and Thomas B. Kornberg \\ Department of Biochemistry and Biophysics, University of California, San Francisco, California 94143 USA
}

\begin{abstract}
A Drosophila strain was isolated that carries a lacZ-bearing recombinant $\mathbf{P}$ element integrated in the cubitus interruptus Dominant (ci-D) locus. This strain expresses $\beta$-galactosidase in the anterior compartments of embryos and imaginal discs, suggesting that expression of ci-D is anterior-compartment specific. DNA from ci$D$ was cloned. In situ hybridization to imaginal discs confirmed that ci-D RNA is present only in anterior compartments. ci-D RNA is also limited to the anterior compartments at the germ-band extension stage of embryonic development, although not at earlier stages. In engrailed mutants, ci-D expression was derepressed in the posterior compartments of both embryos and imaginal discs. We postulate that engrailed, which is expressed in only the posterior compartments of embryos and imaginal discs, represses ci-D in these cells.
\end{abstract}

[Key Words: Drosophila; P element; compartment-specific expression; ci-D expression and repression; engrailed expression]

Received February 7, 1990; revised version accepted March 30, 1990.

The control of early Drosophila development involves $>39$ different genes (Nüsslein-Volhard and Weischaus 1980; Nüsslein-Volhard et al. 1984; Jurgens et al. 1984; Perrimon and Mahowald 1987). Some of these genes are expressed during oogenesis, and after fertilization, their products govern how patterns along the anterior-posterior and dorsal-ventral axes of the embryo are generated. Others are expressed in a temporal program just prior to and/or during gastrulation, and they direct the step-wise refinement of position and acquisition of developmental fate. Understanding the interplay between these regulatory genes and the genes they control promises to reveal much about the processes that generate pattern during early development.

Drosophila segments form in the early gastrula, and from their inception, each comprises an anterior and a posterior developmental compartment. Compartments are groups of cells that do not intermingle with cells of other compartments and that share a common group of ancestral founder cells (Garcia-Bellido et al. 1973). Because anatomical boundaries do not separate adjacent compartments, their developmental segregation must depend on other, as yet unknown, means. One genetic function known to be essential to the integrity of compartments and to the process of segmentation is the engrailed gene.

engrailed is represented by many mutant alleles, most of which disrupt embryonic compartments and segments, and are embryonic lethal (Kornberg 1981a). engrailed mutants also affect adult structures (Lawrence and Morata 1976; Kornberg 1981a,b; Lawrence and Struhl 1982), predominantly those derived from the posterior compartment cells. In the absence of engrailed function, most anterior compartment structures develop normally, whereas many from the posterior compartments are transformed and have a more "anterior" character. Interestingly, engrailed mutant clones arising in the posterior compartment fail to respect the compartment border and mix with anterior cells (Lawrence and Morata 1976). These observations suggest that engrailed is necessary to maintain segmental and compartment boundaries and to specify posterior compartmental identity.

engrailed expression is restricted mostly to the cells of the posterior compartments. In embryos, its patterns of expression have a striped appearance in the epidermal cells, because the compartments form annuli that alternate A-P-A-P-. . . along the embryo axis, and no expression in the anterior compartment cells is detectable (DiNardo et al. 1985; Fjose et al. 1985; Kornberg et al. 1985; Karr et al. 1989). In imaginal discs, engrailed expression is confined to the posterior compartment of each disc, and the patterns are unique to each type of disc (Kornberg et al. 1985; Brower 1986; Hama et al. 1990). Therefore, its realms of expression correlate with its domains of function.

The engrailed gene encodes a single protein of $\sim 58,000$ daltons that has a homeo domain and binds DNA with high affinity (Desplan et al. 1985, 1988; Poole et al. 1985; Hoey and Levine 1988). These characteristics suggest a role in transcriptional regulation, and we have sought to identify genes whose expression engrailed controls. It seems likely that engrailed protein determines posterior compartment identity either by activating those genes that execute posterior compartmentspecific functions or by repressing those that specify an 
anterior fate. Such genes may have patterns of expression that are similar or complementary to those of engrailed.

Recently, a method (termed the "enhancer trap") has been developed that makes it feasible to sample the activity of promoters in the Drosophila genome in a random manner and on a large scale (Bellen et al. 1989; Bier et al. 1989; Wilson et al. 1989|. Such enhancer-trap screens utilize a chimeric lac $Z$ gene with a weak, enhancer-deficient promoter that can be inserted randomly in the genome as part of a recombinant $\mathrm{P}$ element. Transformed lines can then be screened for position- and temporal-specific patterns of lacZ expression. These expression patterns arise when a $P$ element integrates near a strong enhancer of transcription. These expression patterns are apparently representative of the transcription units that are located adjacent to the site of integration and that normally respond to the same enhancers. Because such transcription units can be readily isolated from the transformed strains by exploiting the unique sequences carried by the $P$ element, enhancer-trap screens have the potential to identify genes with particular patterns of expression.

In addition, because the activity of a promoter must reflect, in some way, the pattern of expression of its regulators, screening for transcription patterns that are related to those of a particular regulatory gene may provide a means to identify "downstream" targets. With the goal of identifying regulated targets of the engrailed gene, we conducted an enhancer-trap search for compartment-specific expression patterns in imaginal discs. We thereby identified and cloned a gene with two intriguing properties: a transcription pattern precisely complementary to engrailed and expression that is derepressed in engrailed mutants. Molecular and genetic data indicate that this cloned DNA includes a portion of the cubitus interruptus-D gene (ci-D) (Hochman 1971, 1973, 1976; Orenic et al. 1987).

We note that the genetic complementation between alleles of the Cell $(\mathrm{Ce})$ gene and $C i^{D}$ is complex and that these mutations are likely allelic. To acknowledge our uncertainty about their relationship, in the description that follows, we use $c i^{D}$ to indicate the $c i^{D}$ allele, and $c i-D$ to indicate the locus affected by $c i^{D}$ and Cell alleles. A more extensive description of the relationship between $\mathrm{ci}^{D}$ and $C e$ is in Orenic et al. $(1987,1990)$ and in the Materials and methods.

\section{Results}

\section{Identification and characterization of ci- $\mathrm{D}^{\text {plac }}$}

Patterns of $1 a c Z$ expression were determined in imaginal discs isolated from 500 different Drosophila strains carrying an enhancer-sensitive $\mathrm{P}$ element. Among the strains examined, 49 had discs with spatially restricted patterns. Five expressed $\beta$-galactosidase in patterns that approximated the compartmental organization of imaginal discs. One of these had $\beta$-galactosidase activity exclusively in posterior compartment cells; because its inserted transposon was in the cytological location of the engrailed gene, polytene region $48 \mathrm{~A}$, it was not characterized further. One had $\beta$-galactosidase activity in a pattern similar to wingless, including expression along the dorsal-ventral boundary of the wing disc. Its inserted transposon was in $28 \mathrm{~A}$, the cytological location of wingless. One strain had $\beta$-galactosidase activity along the dorsal-ventral boundary in wing discs, and another had activity along portions of the $\mathrm{A} / \mathrm{P}$ border in all discs. Finally, a strain, $c i-D^{\text {plac }}$, with a single site of integration in region $101 \mathrm{~F}$ of the fourth chromosome (data not shown), had $\beta$-galactosidase exclusively in anterior compartment cells of each imaginal disc (Fig. 1b,e,h). The cells that express $\beta$-galactosidase in these discs include those cells that do not express engrailed, and generate patterns that are precisely complementary to those representing engrailed expression (Fig. la,d,g).

lacZ expression in $c i-D^{\text {plac }}$ was compartment specific during embryonic development as well: staining embryos with an anti- $\beta$-galactosidase antibody revealed that the inserted lac $Z$ gene was active in wide, segmentally repeated stripes (Fig. 2a). Comparison with patterns of engrailed expression (Fig. 2b) suggests that the ci-D plac stripes are in the anterior compartments. Double staining of the embryos with antibodies against both $\beta$ galactosidase and engrailed protein confirmed that these stripes fill the anterior compartments in a manner that precisely complements engrailed (Fig. 2c,d).

The $101 \mathrm{~F}$ insertion has an embryonic lethal effect. Sixty-two percent of the homozygous individuals die before completing embryogenesis. Most of these die without forming a cuticle, although $\sim 10 \%$ make a cuticle with pair-rule-type fusions. In fixed embryo preparations, abnormalities were observed at several stages of development: twisted conformations among gastrulae and segment fusions and failures to complete head involution among older embryos.

The chromosomal position of the P element in $c i-D^{\text {plac }}$ is consistent with integration into either of two segment polarity loci that are contained in the deficiency $M^{62 F[D f(4) 101 E-F ; 102 B 2-5], ~ C e ~ o r ~} \mathrm{Ci}^{D}$ (Hochman 1971, $1973,1976)$. The complementation behavior of $\mathrm{Ce}^{2}$ and $C i^{D}$, and their respective alleles $l(4) 17$ and $l(4) 13$, is complex (Hochman 1971, 1973, 1976; Orenic et al. 1987). Each of these alleles is embryonic lethal when homozygous and produces a segment polarity phenotype. 1(4)13 fully complements $C e^{2}$ and $1(4) 17$ and fails to complement $c i^{D}$. The $c i^{D}$ allele, however, only partially complements $C e^{2}$ and 1(4)17: although most embryos hatch without cuticular abnormalities, they die as pupae or larvae (Orenic et al. 1987). To determine whether the insertion in $c i-D^{p l a c}$ had inactivated either of these loci, we constructed the relevant heterozygotes. $c i-D^{\text {plac }}$ does not fully complement either $c i^{D}$ or $C e^{2}$. It is semilethal over $\mathrm{Ce}^{2}$. Most heterozygous embryos die before making cuticle; those that make cuticle have two or more fused denticle belts. Few zygotes $(1-2 \%)$ survive to adulthood, and although their emergence is delayed, their appearance is normal. $c i^{D} / c i-D^{\text {plac }}$ heterozygotes die shortly before or after eclosion. These flies have abnormal legs and mouthparts, and the wing vein defects 

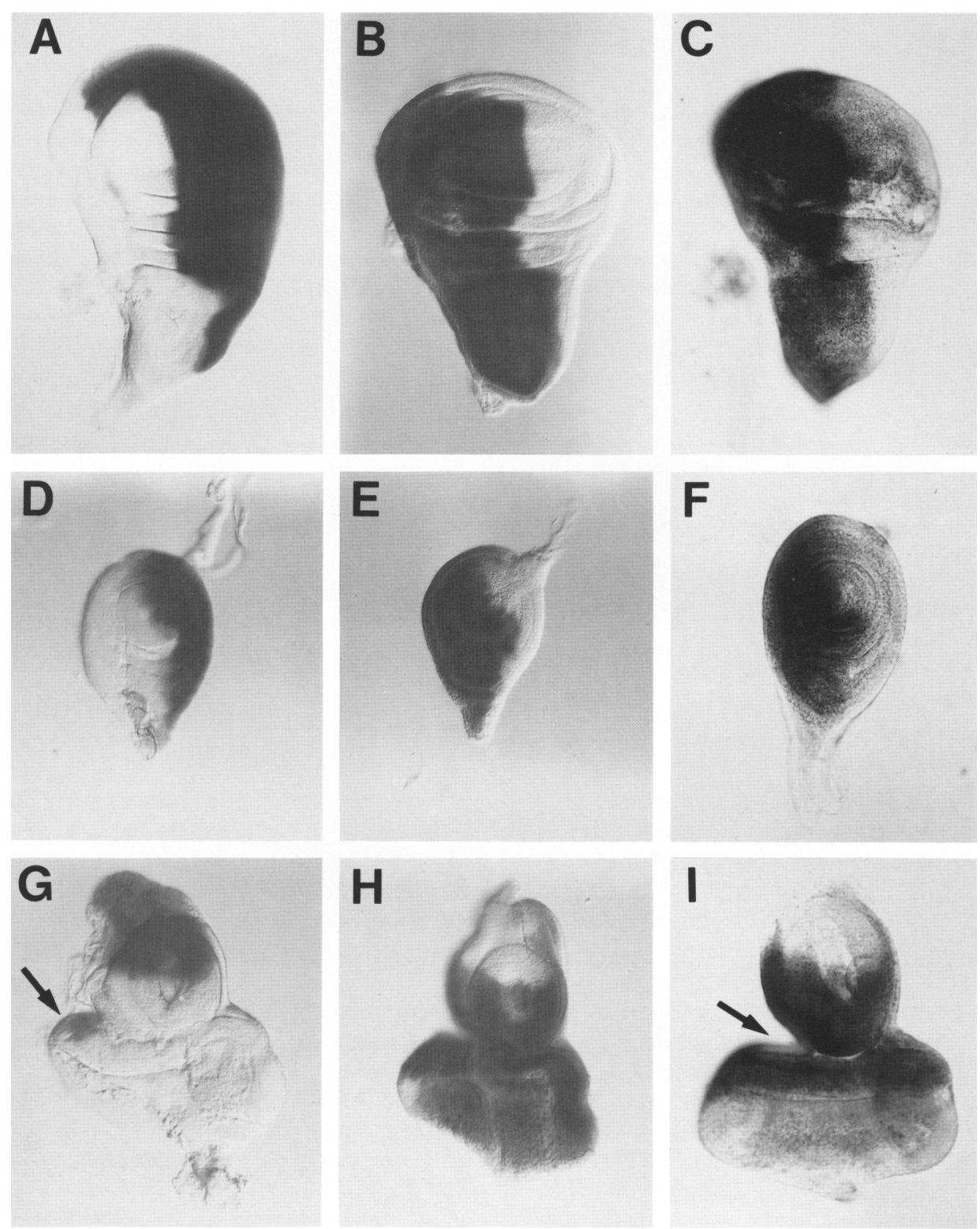

Figure 1. Complementary patterns of $c i-D$ and engrailed expression in imaginal discs. $\beta$-galactosidase was detected with X-gal as described in Materials and methods. ci- $D$ RNA was detected by in situ hybridization with a digoxigenin labeled probe and subsequent binding of an alkaline-phosphatase-conjugated anti-digoxigenin antibody. $(A, D$, and $G) \beta$-galactosidase activity in ryXho25 imaginal discs, which express $\beta$-galactosidase under engrailed control in all posterior compartments. $(B, E$, and $H) \beta$-galactosidase activity in $c i-D^{\text {plac }}$ imaginal discs, which express $\beta$-galactosidase under ci- $D$ control. Note the complementarity of the compartment boundaries in each disc. $(C, F$, and $I) c i-D$ RNA in wild-type imaginal discs. This pattern is virtually identical to the $\beta$-galactosidase pattern in $c i-D^{\text {plac }}$ discs. The arrows in $G$ and $I$ point to the putative ocellar region of the eye/antennal discs, which does not express $c i-D$ RNA but which does show engrailed activity.

characteristic of $c i^{D}$ are exacerbated. Surprisingly, both $1(4) 17$ and 1(4)13 fully complement ci-D plac. The observation that the single P-element insert in ci- $D^{\text {plac }}$ (see below) produces a mutation that does not complement either $C e^{2}$ or $c i^{D}$ indicates that $c i-D^{\text {plac }}$ is an allele of both Cell and cubitus-interruptus, and furthermore, suggests that Cell and cubitus-interruptus share exons or regulatory functions. Although we have assigned this P-element-generated allele the name ci-D plac, we have done so for convenience, not to distinguish between $\mathrm{Cu}$ - bitus-interruptus and Cell. We will henceforth refer to the locus affected by $c i-D^{\text {plac }}$ as $c i-D$.

\section{Cloning of genomic DNA surrounding ci-D plac}

Southern blotting confirmed the presence of a single transposon in ci- $D^{\text {plac }}$, and revealed a single $15-\mathrm{kb} X \mathrm{Xba \textrm {I }}$ fragment that contained both P-element DNA and $\sim 5$ $\mathrm{kb}$ of adjacent genomic sequence. This $\mathrm{XbaI}$ fragment was cloned from a genomic library that had been pre- 
pared with size-selected DNA from ci-D plac flies. A 5.1$\mathrm{kb} X b a \mathrm{I}-H i n d I I I$ fragment from this clone hybridized to a $15-\mathrm{kb}$ genomic $\mathrm{XbaI}$ fragment that comigrated with the fragment detected with a P-element probe. There may be, in addition, sequences related to the $5.1-\mathrm{kb}$ $X b a I-H i n d I I I$ fragment elsewhere in the genome: the $5.1-\mathrm{kb}$ probe also hybridized to a $19-\mathrm{kb} \mathrm{XbaI}$ fragment, although somewhat less intensely, and EcoRI and SstI digests also yielded two fragments that hybridized with this probe.

DNA from this region of the genome has been cloned independently in the Holmgren laboratory (Orenic et al. 1990). The 5.1-kb HindIII-XbaI fragment hybridized to phage and cosmid clones they had isolated in their efforts to clone the $c i-D$ gene. Our analysis indicates that the $\mathrm{P}$ element in $c i-D^{\text {plac }}$ inserted near the first exon of the $c i-D$ transcription unit they identified. The orientation of lacZ in the inserted $\mathrm{P}$ element is opposite to that of the $c i-D$ transcript.

ci-D expression in wild-type imaginal discs and embryos

To determine whether regulation of $l a c Z$ in $c i-D^{\text {plac }}$ ima- ginal discs reflects the manner by which $c i-D$ is normally controlled, we performed in situ hybridizations with a probe made from a $c i-D$ cDNA clone. This cDNA was kindly provided by T. Orenic and R. Holmgren (Orenic et al. 1990|. These experiments confirmed that expression of the enhancer-trap plasmid in imaginal discs accurately mimics the resident $c i-D$ locus (Fig. $1 \mathrm{c}, \mathrm{f}, \mathrm{i}$ ). Like the $l a c Z$ gene in $c i-D^{\text {plac }}$, the $c i-D$ locus in wild-type imaginal discs is expressed specifically in the imaginal anterior compartment cells. Only in the eye/antennal disc were slight differences noted (although these differences are probably best attributed to the better spatial resolution of the in situ hybridization method): the relative abundance of $c i-D$ RNA was lower in the developing eye, and no $c i-D$ RNA was present in the region that will give rise to the ocellus. In contrast, $\beta$-galactosidase activity in these regions was high. Because engrailed is expressed slightly in the region of the developing eye and strongly in the putative ocellar region (Fig. $1 \mathrm{~g}$ ), the in situ patterns are probably a more accurate indication of the reciprocity of engrailed and $c i-D$ expression.

A similar analysis of wild-type and $c i-D^{\text {plac }}$ embryos yielded similar results: the patterns were identical at most stages, although several inconsistencies were
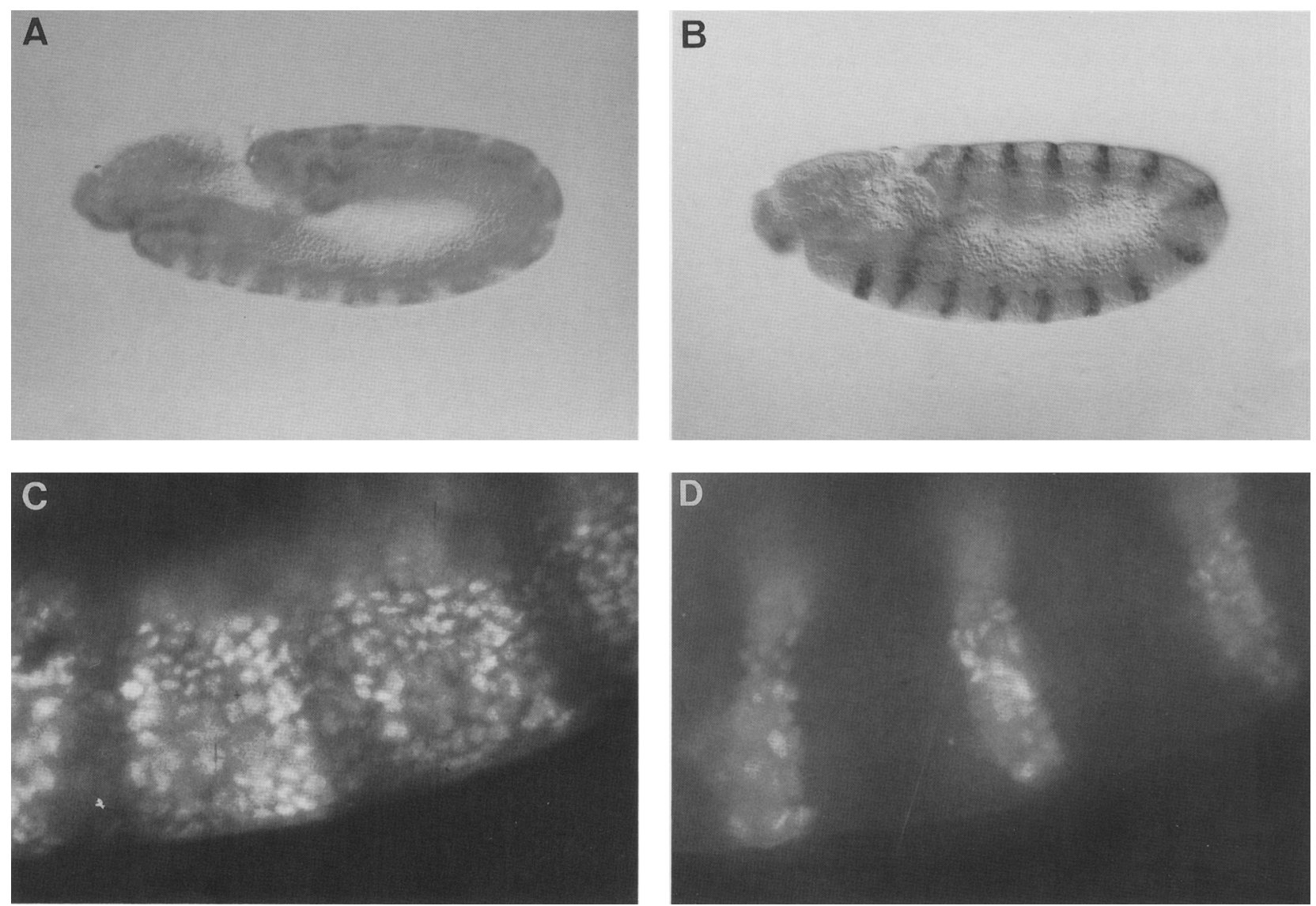

Figure 2. Complementary patterns of ci-D and engrailed expression in embryos revealed with antibodies to $\beta$-galactosidase and engrailed proteins. (A) A ci-D plac embryo stained with an antibody to $\beta$-galactosidase. $(B) \mathrm{A}$ wild-type embryo stained with an anti-engrailed antibody. $(C$ and $D)$ A stage $10 \mathrm{ci}$ - $D^{\text {plac }}$ embryo stained with antibodies to both $\beta$-galactosidase $(C)$ and $e n g r a i l e d(D)$. These are composite photographs assembled electronically after separately recording fluorescein and rhodamine fluorescence with a microscope equipped with a Charge Coupled Device. 
noted. Both $\beta$-galactosidase and $c i-D$ RNA are present as early as nuclear cycle 9 , five division cycles before cellular blastoderm formation. Both appear to be concentrated over every nucleus (Fig. 3a). After blastoderm formation, $c i-D$ RNA becomes concentrated in three broad bands that are most intense dorsally, and less intense in the most ventral $1 / 4$ of the embryo (Fig. $3 \mathrm{~b}, \mathrm{c}$ ). The anteriormost band of expression marks the region where the cephalic furrow will form, leaving most of the presumptive head region devoid of $c i-D$ RNA at this stage. Because some embryos have uniform expression at this stage (data not shown), it seems likely that ubiquitous expression changes to patterned expression during cellularization and before gastrulation. Among ci-D $D^{\text {plac }} \mathrm{cel}$ lular blastoderm embryos stained with an anti- $\beta$-galactosidase antibody, only uniformly stained embryos were observed (Fig. 4a).
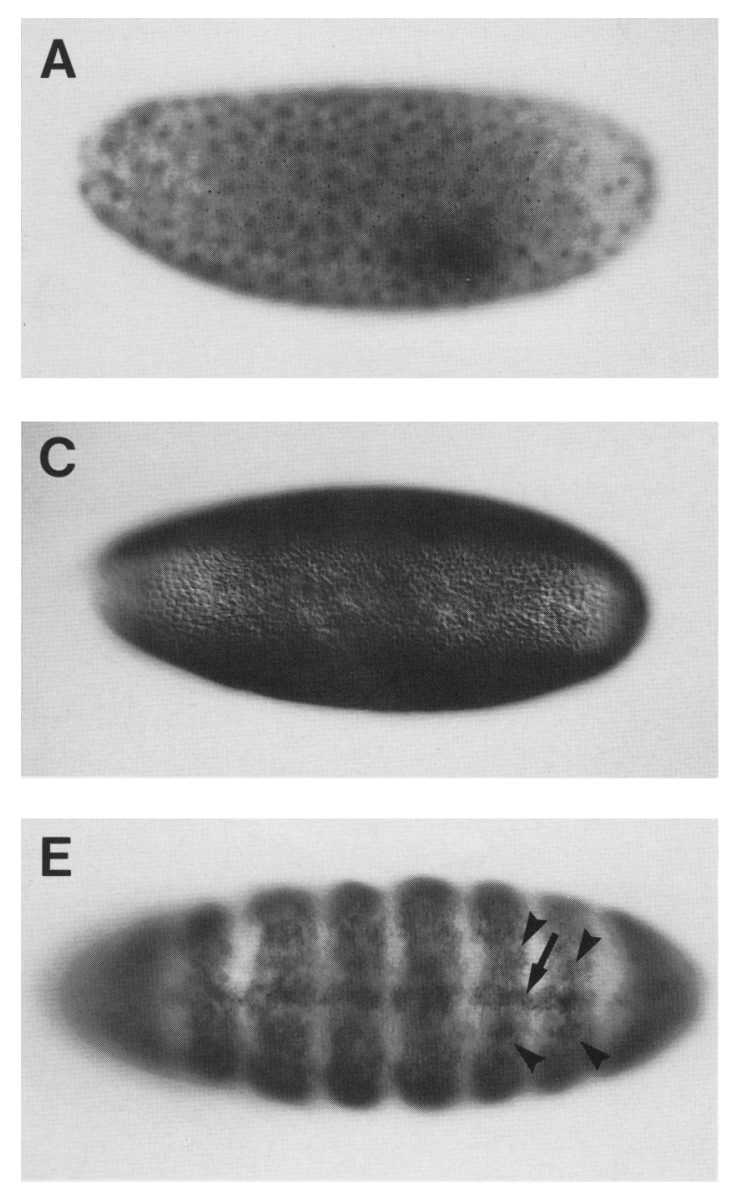

Throughout germ-band extension and shortening, patterns of $\beta$-galactosidase activity in $c i-D^{\text {plac }}$ embryos that are developing normally and $c i-D$ RNA in wild-type embryos are indistinguishable. As the germ-band begins to extend, $c i-D$ RNA condenses into segmentally repeated stripes. The most anterior stripes appear first. By the time the germ band is fully extended, both $c i-D$ RNA and $\beta$-galactosidase activity are expressed in 14 stripes that comprise the anterior compartment of each segment (Figs. 2a,c and 3d,e). About $20 \%$ of ci-D plac germband extended embryos have an abnormal pattern of $\beta$ galactosidase activity; they have $\beta$-galactosidase activity uniformly, or abnormally striped, with two or more anterior compartment-specific stripes fused (Fig. 4b). In situ hybridization confirmed that a subset of $c i-D^{\text {plac }}$ homozygotes express ci-D RNA uniformly or in a segmentally fused pattern at germ-band extension. This pecu-
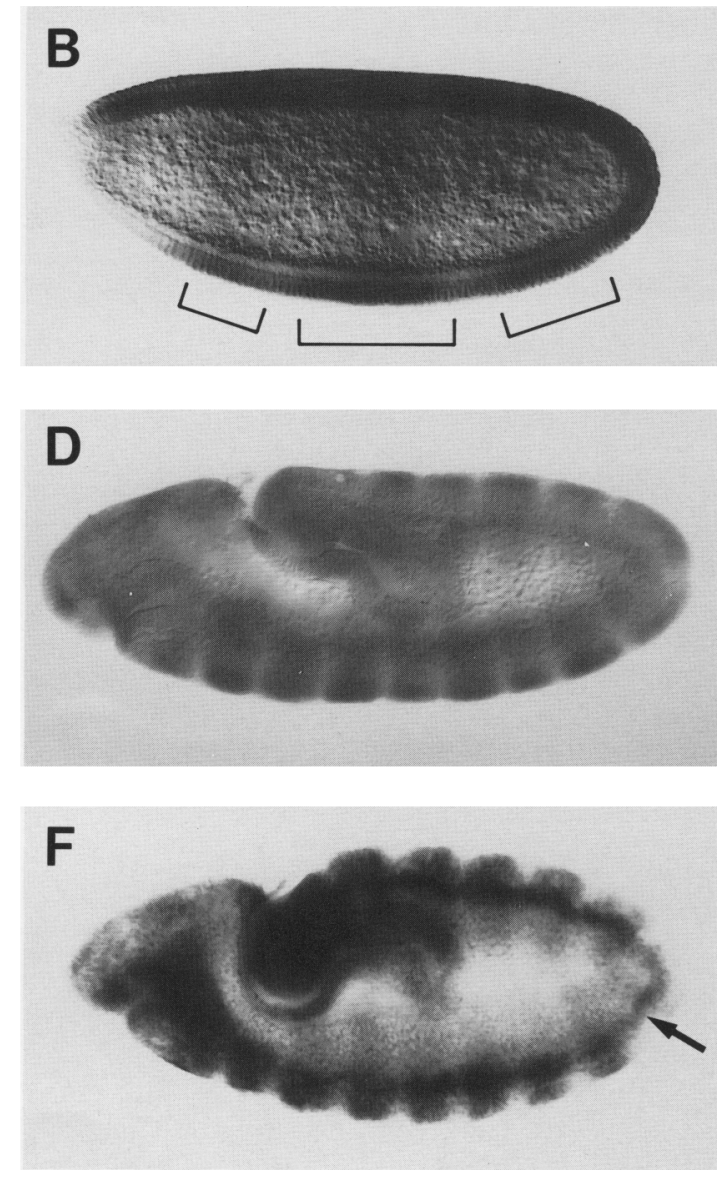

Figure 3. Expression of $c i-D$ RNA in wild-type embryos. RNA was detected using a digoxigenin-labeled probe derived from a 1-kb cDNA representing the $3^{\prime}$ end of the ci-D transcript (Orenic et al. 1990). In each case, the anterior direction is to left. $(A)$ Staining can be observed in spots that appear to be over nuclei in a stage 3 embryo. $(B$ and $C)$ Late stage 5 embryos, after cellularization is completed. The embryo in $B$ is viewed laterally, and somewhat dorsally. At this stage, $c i-D$ RNA is absent from the anteriormost ventral region. It is concentrated in three broad bands (brackets), and is also present posteriorly. The central band is $\sim 2 \times$ as wide as the others. A ventral view of the embryo $(C)$ shows that staining is weakest in a strip comprising the ventralmost $1 / 4$ of its surface. $(D)$ Stage 11, lateral view, showing ci-D RNA in wide, anterior stripes. (E) Stage 10, viewed ventrally and focused on the neuroblast layer beneath the ectoderm where staining of midline cells is evident (arrow). Staining is also apparent in some cells which straddle the midline (arrowhead). $(F)$ Stage 11, viewed laterally and focused on a line of cells located at the bottom of the neuroblast layer that may be either neuronal or mesodermal (arrow). (G) Stage 17, viewed laterally, shows ci-D RNA on the dorsal side of the ventral nerve cord and in parts of the subesophageal ganglia. 
liarity correlates with the semi-penetrant pair-rule phenotype of $c i-D^{\text {plac }}$.

$c i-D$ is also expressed in the developing embryonic nervous system. Both $c i-D$ RNA and $c i$ - $D^{\text {plac }} \beta$-galactosidase activity is present in cells underlying the epidermal layer, along or straddling the ventral midline in stage 10 embryos (Fig. 2e). Lateral views suggest that some of these may be mesectodermal cells (Fig. 2f).

\section{ci-D expression is derepressed in engrailed mutants}

The complementarity of engrailed and ci-D patterns of expression in imaginal discs and germ-band extended embryos suggests that one gene might regulate the other. To examine the role of the engrailed gene product in $c i-D$ expression, we constructed a stock with the genotype $w$; $\mathrm{en}^{1}$; ci- $D^{\text {plac }}$. In $e \mathrm{n}^{1}$ wing discs, engrailed protein is often absent in the posterior wing pouch (Brower 1986). We were able to detect ectopic expression of $\beta$-galactosidase in the posterior wing pouch in $\sim 30 \%$ of $e n^{1}$ discs, suggesting that $c i-D$ expression was no longer confined to the anterior compartment in these discs (Fig. $5 \mathrm{~b})$. We also examined the effect of the engrailed deficiencies $X 31$ and $I O 34$ on ci-D expression in embryos. In each case, the expected Mendelian proportion of embryos had an engrailed phenotype, and mutant gastrulaes had altered ci-D expression. Expression was normal until germ-band extension; engrailed embryos [identified unambiguously at cellular blastoderm by the position of their pole cells (Karr et al. 1985)] had ci-D RNA patterns indistinguishable from wild type. After this stage, however, stripes failed to form; instead, ci-D expression remained uniform throughout the germ band (Fig. 5a,d; cf. with Fig. 5c and Fig. 3d). Embryos with altered expression correlated exactly with those with an engrailed phenotype (i.e., segment fusions, incomplete or skewed germ-band extension). Thus, in both embryos and imaginal discs, the engrailed gene product is necessary to prevent expression of $c i-D$ in the posterior compartments. The relationship is not reciprocal, however: examination of the engrailed expression pattern in $\mathrm{Ci}^{D}$ and $\mathrm{Ce}^{2}$ homozygotes revealed no derepression of engrailed in anterior compartments (data not shown).

\section{Discussion}

$c i \cdot D$ is one of the many genetic functions that help regulate segmentation of the Drosophila embryo. It has been included among the segment polarity class of segmentation genes (Nüsslein-Volhard and Wieschaus 1980) because its mutant alleles alter segmentation with a single segment periodicity. We have isolated a new mutant that is allelic to $c i-D, c i-D^{\text {plac }}$, in which an integrated $\mathrm{P}$ element inactivates $c i-D$; and we have cloned the mutated region of the ci-D plac chromosome. We find that expression of $c i-D$ mRNA is consistent with the role of $c i-D$ in segmentation, and that the regulatory relationship of $c i-D$ with another segmentation gene, engrailed, is likely to be intimate.

In the ectoderm of germ-band extended embryos and
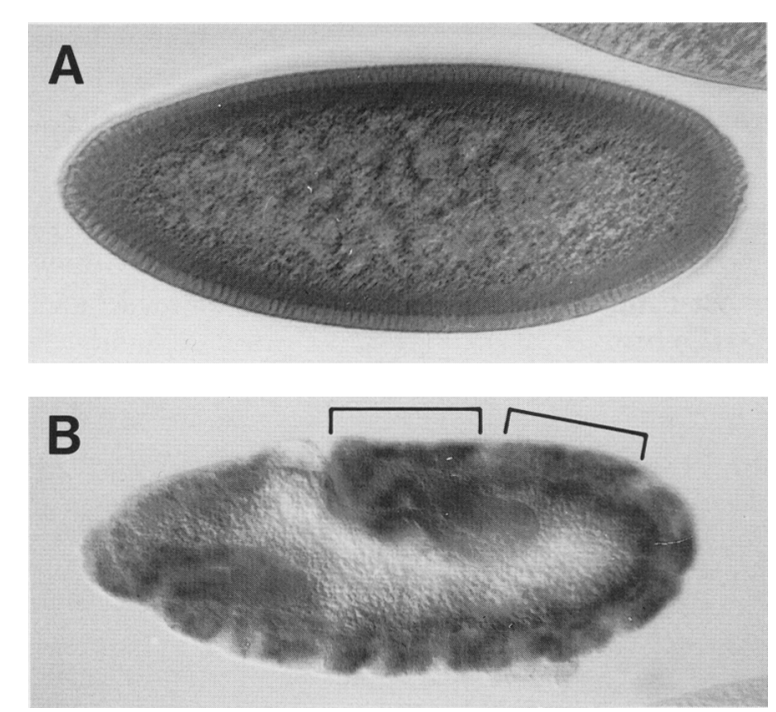

Figure 4. Aberrant $c i-D$ activity in ci- $D^{p l a c}$ embryos as revealed by $\beta$-galactosidase activity and in situs. $(A) \beta$-Galactosidase activity in stage $5 \mathrm{ci}-D^{\text {plac }}$ embryos is uniform, unlike wild type. $(B)$ Some $c i$ - $D^{\text {plac }}$ embryos show $\beta$-galactosidase activity in stripes that are two segments wide (brackets).

in imaginal discs, patterns of ci-D and engrailed expression are precisely complementary. ci-D is expressed only in anterior compartment cells, and engrailed is expressed only in posterior compartment cells. Moreover, limiting $c i-D$ expression to the anterior compartment cells depends on engrailed: in embryos and imaginal discs of engrailed mutants, $c i-D$ is derepressed in posterior compartments. This provides a clear indication that engrailed is performing the same function in both the embryo and imaginal discs and suggests that one mechanism by which engrailed specifies posterior developmental fate is through repression of $c i-D$.

$c i-D$ and engrailed have a number of similar properties. For instance, both expression of $\beta$-galactosidase in $c i-D^{\text {plac }}$ and in situ detection of $c i-D$ RNA indicate that $c i-D$ is expressed in at least two different modes. In prestage 7 embryos, expression is uniform or nearly so and does not correlate with the segmental or compartmental organization of the embryo. However, after this stage, expression is specific to anterior compartment cells of the epidermis. Similarly, engrailed is expressed in a compartment-specific manner in the epidermis, and in nonsegmental patterns prior to gastrulation (DiNardo et al. 1985; Fjose et al. 1985; Karr et al. 1985, 1989; Kornberg et al. 1985).

Expression of both $c i-D$ and engrailed in precellular embryos correlates with the precellular phenotypes of their respective mutant alleles. Both $c i^{D}$ and $C e^{2}$ mutants suffer developmental abnormalities as early as nuclear cycle 7 (S. Eaton and T. Kornberg, unpubl.). As with engrailed (Karr et al. 1985), homozygous mutant precellular embryos are mitotically asynchronous. $c i-D^{p l a c}, C e^{2}$ and $c i^{D}$ mutants also gastrulate abnormally (unpubl.); in many cases the cephalic furrow forms late or is placed incorrectly, and the germ band extends at an abnormal 
angle with respect to the cephalic furrow. Gastrulation of engrailed mutants is also bilaterally asymmetric (Karr et al. 1985). We do not understand what the role of $c i-D$ or engrailed may be in these processes.

Similarly, although both ci-D and engrailed mutants have severe segmentation defects, there is no obvious way to explain how expression of these genes correlates with these defects. For engrailed, it is difficult to understand how mutations in a gene that functions in the posterior compartment of every segment can cause pairwise segment fusions. For $c i-D$, the pattern elements deleted in $C e^{2}$ and $c i^{D}$ homozygotes do not correlate simply with structures that are produced by the anterior compartment cells. Recently, the larval structures derived from engrailed-expressing posterior compartment epidermal cells have been identified (Hama et al. 1990). Combining this information with the description of the $C e^{2}$ and $c i^{D}$ cuticular phenotypes provided by Orenic et al. (1987), we conclude that: (1) Dorsally, $C e^{2}$ larvae are missing posterior structures as well as structures derived from the anteriormost cells in the adjacent anterior compartment. Ventrally, however, they are missing posterior structures as well as structures derived from the posteriormost cells in the adjacent anterior compartment; (2) ventrally, $c i^{D}$ homozygotes delete only posterior structures, but dorsally, they are missing only structures derived from the posteriormost cells of anterior compartments. Therefore, although ci-D RNA is confined to anterior compartments at some stages, it does not seem to be essential for the formation of anterior pattern elements; $c i^{D}$ homozygotes, in which $c i-D$ RNA is absent, make most anterior structures. Indeed, only the posterior compartment is affected ventrally. The adult structures affected by $c i^{D}$ heterozygotes are not derived from anterior compartments either. Although $c i-D$ RNA is expressed in the anterior compartment of wing imaginal discs, $c i^{D}$ affects only the fourth wing vein, a posterior element.

The pair-rule phenotype observed in $c i-D^{\text {plac }}$ homozygotes is noteworthy. Ten percent of homozygous $c i-D^{\text {plac }}$ embryos make a cuticle with segment fusions similar to those of engrailed homozygotes. In addition, some ci$D^{\text {plac }}$ embryos have uniform expression of both $\beta$-galactosidase and ci-D RNA - a pattern identical to that observed in engrailed mutants. This raises the possibility that the $c i-D^{\text {plac }}$ insertion interferes with regulation of $c i-D$ such that $c i-D$ is not repressed by engrailed. If this were so, then the inappropriate expression of $c i-D$ might account entirely for the pair-rule fusions observed in ci$D^{\text {plac }}$ and engrailed mutants. Although we do not know the mechanism by which the engrailed protein represses $c i-D$, the interaction could be direct, involving binding of engrailed protein to ci- $D$ regulatory elements. Repression of $c i-D$ in posterior compartments in the embryo was first observed 10-40 min after engrailed expression appears in its 14-stripe segmental pattern. This delay would be consistent with a direct role for engrailed if the half-life of ci-D RNA is not unusually short. Alternatively, this delay may reflect an intermediate step, whereby engrailed protein activates another gene that directly mediates $c i-D$ repression. The fact that $c i-D$ and engrailed expression are not complementary early in embryogenesis superficially supports the latter hypothesis. On the other hand, our preliminary results suggest that DNA surrounding the $c i-D$ transcription unit, including the site of $c i-D^{\text {plac }}$ insertion, has high affinity binding sites for engrailed protein (S. Eaton and M.T. Saenz-Robles, unpubl.). Functional studies of these binding sites necessary to explore this possibility are in progress.

Other than the observation that engrailed represses $c i-D$ in posterior compartments, little is known concerning how engrailed determines posterior compartment identity. We assume that engrailed regulates a battery of other genes, but we do not know their identity. There are at least 10 strong and numerous weak binding sites for engrailed protein on the salivary chromosomes (F. Maschat and T. Kornberg, unpubl.). If these sites represent other genes regulated by engrailed, it is possible that some are also expressed in a compartmentspecific manner. If so, our ongoing screens of additional enhancer trap lines may succeed in isolating them.

\section{Materials and methods}

\section{Fly culture and fly strains}

Flies were maintained at $25^{\circ} \mathrm{C}$ on standard molasses medium. Wild type refers to an Oregon $\mathrm{R}$ line. Alleles of $c i$ and Cell were obtained from the Bowling Green Stock Center or from T. Orenic and are described in Lindsley and Grell (1968). engrailed allele $X 31$ (Kornberg 1981a) is deleted for both the engrailed and invected genes as well as several neighboring transcription units (Kuner et al. 1985). engrailed allele IO34 (Nüsslein-Volhard and Wieschaus 1980) deletes a portion of the engrailed coding sequence and disrupts the subsequent reading frame ( $E$. Gustavson and T. Kornberg, unpubl.). Stages are according to Campos-Ortega and Hartenstein (1985).

Although their genetic structure and relationship is uncertain, we considered Cell and $c i \cdot D$ to represent different types of mutations in the same gene. Both are located within a small interval of the fourth chromosome between $101 \mathrm{E}-\mathrm{F}$ and 102B2-5. In addition, existing Cell and $c i-D$ mutants have similar segmentation phenotypes, and transheterozygotes complement each other in complex ways (Orenic et al. 1987). ci- $D^{\text {plac }}$, whose inserted transposon is located either in an intron or is immediately adjacent to the $c i-D$ transcription unit, fails to complement either the embryonic lethality of $C e^{2}$ or the adult defects of $c i^{D}$. In addition, $c i-D^{\text {plac }}$ disrupts the spatial regulation of the $c i-D$ transcript in embryos. Because in situ hybridization to $C e^{2}$ mutant embryos with a $c i-D$ cDNA probe also reveals abnormal spatial regulation of $c i-D$ (S. Eaton and T.B. Kornberg, unpubl.), and because no $c i-D$ transcripts were detected in $c i^{D}$ homozygotes (Orenic et al. 1990), $C e^{2}$ and $c i^{D}$ may be different regulatory mutations in the same gene.

Preparation of genomic DNA, Southern blot analysis, and cloning of genomic DNA

Genomic DNA for Southern analysis and cloning was prepared from $\sim 100$ flies by use of a procedure based on Jowett (1986). Flies were homogenized in $2 \mathrm{ml}$ of $0.1 \mathrm{M}$ Tris $(\mathrm{pH} 9.0), 0.1 \mathrm{M}$ EDTA, $1.0 \%$ SDS, and $0.5 \%$ diethylpyrocarbonate (DEPC), and were heated at $65^{\circ} \mathrm{C}$ for $30 \mathrm{~min}$. Two hundred and eighty microliters of $8 \mathrm{M} \mathrm{KOAC}$ was added, and the mixture was chilled 

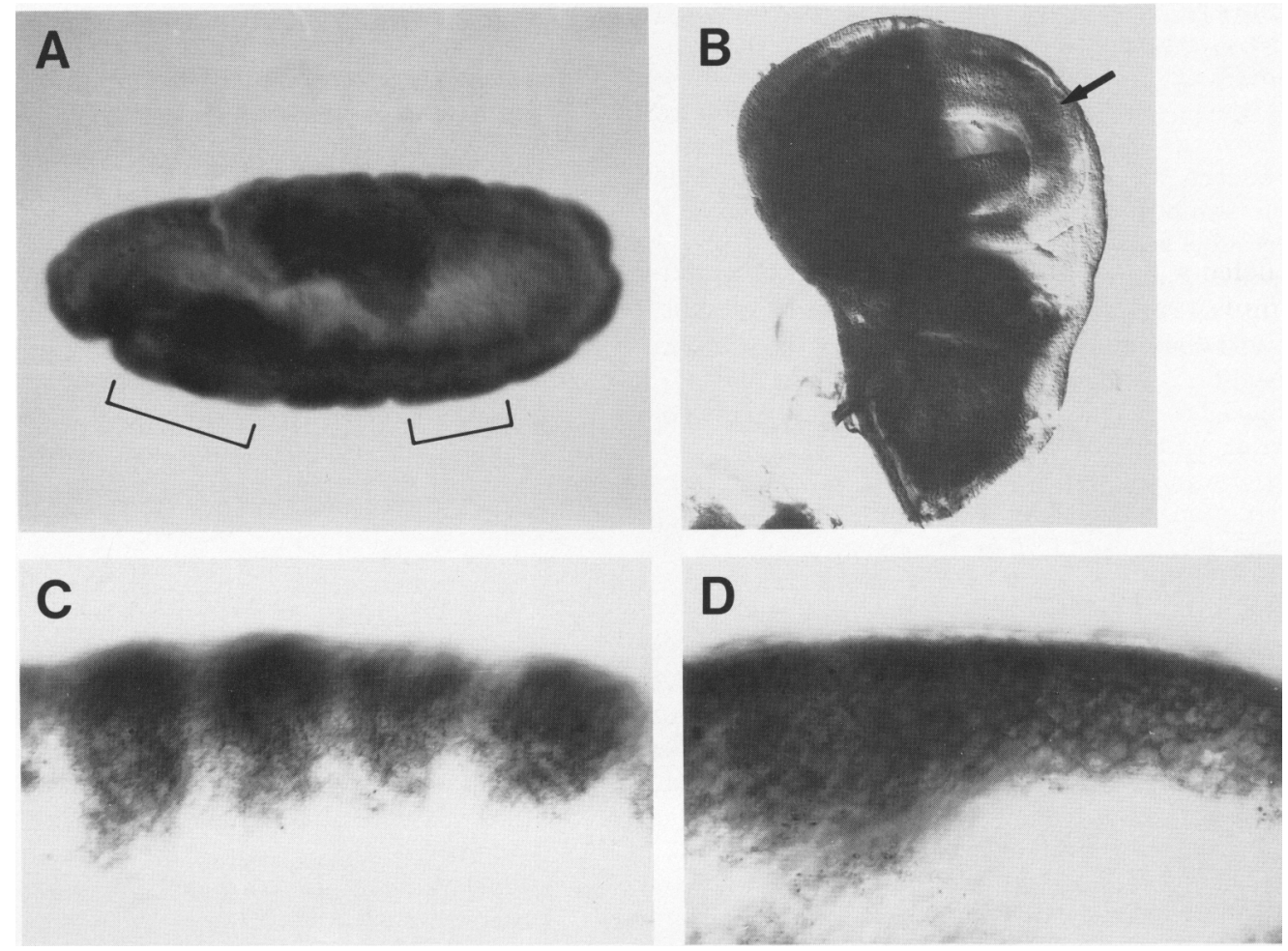

Figure 5. Derepression of $c i-D$ expression in the posterior compartments of engrailed embryos and imaginal discs. $(A)$ An en ${ }^{\text {iO34/ }}$ $e n^{\mathrm{IO} 34}$ stage 11 embryo showing characteristic segment fusions (arrows) and uniform expression of $c i-D$ RNA as detected by in situ hybridization (compare with Fig. 3D). (B) Wing disc from an $e n^{1} / e n^{1} ; c i-D^{\text {plac }} / c^{-}$- $D^{\text {plac }}$ third-instar larva showing derepression of $\beta$-galactosidase in the posterior wing pouch. $(C)$ ci expression in wild-type ectoderm at stage $11 .(D) c i$ expression in en $n^{1034} / e n^{1034}$ ectoderm at stage 11 .

on ice for $30 \mathrm{~min}$ and clarified by centrifugation in an Eppendorf centrifuge at $4^{\circ} \mathrm{C}$ for $10 \mathrm{~min}$. The DNA in the supernatant was precipitated with isopropanol and washed in $70 \%$ ethanol, dried, and resuspended in TE $10 \mathrm{~mm}$ Tris $\mid \mathrm{pH} 7.5), 1 \mathrm{~mm}$ EDTA].

Genomic DNA from the region surrounding the P-element insert was cloned by isolating 14.5-15.5-kb genomic $X b a I$ fragments from an agarose gel and ligating them with $\lambda 2001$ arms that had been digested with $\mathrm{Xbal}$ and phosphatased (Maniatis et al. 1982). Phage were packaged, and the resulting size-selected library was probed with nick-translated P-element DNA. Positive clones were obtained with a frequency of 1 per $10^{4}$, and all had incorporated the same $15-\mathrm{kb} \mathrm{XbaI}$ fragment.

\section{Detection of $\beta$-galactosidase with $X$-gal}

Imaginal discs were dissected from third-instar larvae in phos phate-buffered saline (PBS), fixed with ice cold $0.2 \%$ glutaraldehyde in PBS, washed twice in PBS, and placed in X-gal 15 bromo-4-chloro-3-indolyl-b-D-galactopyranoside) staining solution [0.2\% X-gal (diluted from an $8 \%$ stock in DMSO), $10 \mathrm{~mm}$ $\mathrm{NaPP}_{\mathrm{i}}(\mathrm{pH} 7.0), 1.0 \mathrm{mM} \mathrm{MgCl}_{2}, 5 \mathrm{mM} \mathrm{K}_{4} \mathrm{FE}(\mathrm{CN})_{6}$, and $5 \mathrm{~mm}$ $\left.\mathrm{K}_{3} \mathrm{FE}(\mathrm{CN})_{6}\right)$. Discs were stained from 1 to $16 \mathrm{hr}$ at $37^{\circ} \mathrm{C}$, washed in staining solution that did not contain X-gal, and mounted in fluoromount.

In situ hybridization to whole mount embryos and imaginal discs

The whole mount in situ hybridization procedure was based on the protocol developed by $\mathrm{D}$. Tautz and C. Pfeifle and modified by $\mathrm{C}$. Oh and $\mathrm{B}$. Edgar using Genius TM nonradioactive DNA labeling and detection kit (Boehringer-Mannheim).

Probes for in situ hybridization were labeled with digoxigenin-modified UTP (dig-UTP) by the random priming method. Gel-purified DNA (100 ng) was combined with $7 \mu$ l of primers $\left[\mathrm{pd}(\mathrm{N})_{6}\right.$ random primers at $10 \mathrm{mg} / \mathrm{ml}$; Pharmacial and the volume was brought to $10 \mu \mathrm{l}$ with $\mathrm{H}_{2} \mathrm{O}$. This mixture was boiled for $3 \mathrm{~min}$, quick-chilled in a dry ice-ethanol bath, and added to the following: $2 \mu \mathrm{l}$ of $10 \times$ Vogel buffer $[475 \mathrm{~mm}$ HEPES (pH 6.6), $25 \mathrm{mM} \mathrm{MgCl}_{2}, 52 \mathrm{mM} \beta$-mercaptoethanol], 2.0 $\mu \mathrm{l}$ of Boehringer nucleotide mix with dig-UTP, $1 \mu$ l of $5-10$ units) Klenow, $5 \mu \mathrm{l}$ of $\mathrm{H}_{2} \mathrm{O}$. The reaction was allowed to proceed at $14^{\circ} \mathrm{C}$ for $2 \mathrm{hr}$ and then at room temperature for $1 \mathrm{hr}$. The probe was precipitated with ethanol and resuspended in $50 \mu \mathrm{l}$ of hybridization solution $150 \%$ formamide, $5 \times$ SCC, $100 \mu \mathrm{g} / \mathrm{ml}$ sonicated salmon sperm DNA, $50 \mu \mathrm{g} / \mathrm{ml}$ heparin, $0.1 \%$ Tween 201.

Embryos were collected in PBT (PBS with $0.1 \%$ Tween 20), washed, dechorionated in $50 \%$ bleach for $90 \mathrm{sec}$, and washed with water. The embryos were fixed by shaking at high speed for $20 \mathrm{~min}$ in a two-phase mixture consisting of $4 \mathrm{ml}$ of heptane and $1 \mathrm{ml}$ of fixation solution [0.1 M HEPES (pH 6.9), $2 \mathrm{~mm}$ $\mathrm{MgSO}_{4}, 1 \mathrm{~mm}$ EGTA, 4\% paraformaldehyde]. After fixation, embryos were devitellinized by removal of the fixative, addition of $5 \mathrm{ml}$ of cold methanol, and vigorous shaking for $30 \mathrm{sec}$. The embryos were then washed twice with methanol, and once with methanol/EGTA ( $90 \%$ methanol, $10 \% 0.5 \mathrm{M}$ EGTA). Embryos were post-fixed by washing for 5 min each in $7: 3$ ME : PP [(ME) methanol/EGTA, (PP) $4 \%$ paraformaldehyde in 
PBS], $5: 5 \mathrm{ME}: \mathrm{PP}, 3: 7 \mathrm{ME}: \mathrm{PP}$ and $20 \mathrm{~min}$ in PP. Embryos were then dehydrated and stored at $-20^{\circ} \mathrm{C}$ in $70 \%$ ethanol.

All reagents used in the following steps were treated with diethylpyrocarbonate and autoclaved. Before hybridization, embryos were rehydrated and washed $3 \times$ in PBT. They were then incubated between 3 and $5 \mathrm{~min}$ in $50 \mu \mathrm{g} / \mathrm{ml}$ proteinase $\mathrm{K}$ (the exact time determined by titration of each lot of proteinase $\mathrm{K}$ ). Protease digestion was stopped by incubation for $2 \mathrm{~min}$ in freshly prepared $2 \mathrm{mg} / \mathrm{ml}$ glycine. The embryos were then washed $2 \times$ in PBT, fixed for $20 \mathrm{~min}$ in PP, washed $5 \times$ in PBT, $1 \times$ in $1: 1 \mathrm{PBT} /$ hybridization solution, and $1 \times$ in $100 \%$ hybridization solution. Embryos were prehybridized at $45^{\circ} \mathrm{C}$ for 1 $\mathrm{hr}$ and hybridized overnight at $45^{\circ} \mathrm{C}$ with probe diluted fivefold in hybridization solution.

After hybridization, embryos were washed for $20 \mathrm{~min}$ in hybridization solution, followed by a series of 20 -min washes in increasing concentrations of PBT in hybridization solution 120 , $40,60,80$, and $100 \%)$. They were then washed once more in PBT for $20 \mathrm{~min}$. Goat anti-digoxigenin antibody was diluted 2000 -fold in PBT with 5\% normal goat serum and incubated with the embryos for $1 \mathrm{hr}$. Embryos were then washed $5 \times$ in PBT and $2 \times$ in developing solution $[100 \mathrm{mM} \mathrm{NaCl}, 50 \mathrm{~mm}$ $\mathrm{MgCl}_{2}, 100 \mathrm{mM}$ Tris (pH 9.5), $0.1 \%$ Tween-20, $1 \mathrm{~mm}$ Levamisole). Developing solution containing $4.5 \mu \mathrm{l}$ of NBT (1 ml) and $3.5 \mu \mathrm{l}$ of X-phosphate (vials 9 and 10 of Genius kit) were then added, and the reaction allowed to proceed for $15 \mathrm{~min}$ to 1 hr. Embryos were then dehydrated, cleared with xylene, and mounted in either permount or a Canada Balsam/xylene mixture.

Hybridization to imaginal discs was performed similarly with the following exceptions: Imaginal discs were dissected and collected on ice and washed $3 \times$ in PBS. They were then fixed for $20 \mathrm{~min}$ at $4^{\circ} \mathrm{C}$ in fixation solution (described above) that also contained $0.1 \%$ Triton X-100 and $0.1 \%$ deoxycholate. After five washes with PBT, the discs were treated for $1-2 \mathrm{~min}$ with 10 $\mu \mathrm{g} / \mathrm{ml}$ proteinase $\mathrm{K}$.

\section{Immunological detection of engrailed and $\beta$-galactosidase in embryos}

Immunohistochemical detection of $\beta$-galactosidase and engrailed was essentially as described in Karr et al. (1989). For double-staining embryos, $\beta$-galactosidase antibodies were detected with rhodamine-conjugated secondary antibodies and engrailed antibodies were detected with FITC-conjugated secondary antibodies.

\section{Acknowledgments}

We thank L. and Y.-N. Jan for sharing a portion of their enhancer trap lines; E. Giniger, N. Patel, and R. Bodmer for helpful discussion; Z. Kam and J. Sedat for assistance with optical sectioning; and T. Orenic and R. Holmgren for their cooperation and patience. This work was supported by a Jane Coffin Childs Memorial Fund postdoctoral fellowship to S.E. and a grant from the National Institutes of Health to T.B.K

\section{References}

Bellen, H., C. O'Kane, C. Wilson, U. Grossniklaus, R.K. Pearson, and W.J. Gehring. 1989. P-element-mediated enhancer detection: A versatile method to study development in Drosophila. Genes Dev. 3: 1288-1300.

Bier, E., H. Vaessin, S. Shephard, K. Lee, K. McCall, S. Barbel, L. Ackerman, R. Carretto, T. Uemura, E. Grell, L. Jan, and Y.N. Jan. 1989. Searching for pattern and mutation in the Droso- phila genome with P-lacZ vector. Genes Dev. 3: 12731287.

Brower, D. 1986. engrailed gene expression in Drosophila imaginal discs. EMBO I. 5: 2649-2656.

Campos-Ortega, J.A. and V. Hartenstein. 1985. The embryonic development of Drosophila melanogaster. Springer-Verlag, Berlin.

Desplan, C., J. Theis, and P.H. O'Farrell. 1985. The Drosophila developmental gene engrailed encodes a sequence-specific DNA binding activity. Nature 318: 630-635.

1988. The sequence-specificity of homeodomain-DNA interaction. Cell 54: 1081-1090.

DiNardo, S. and P.H. O'Farrell. 1987. Development of embryonic pattern in $D$. melanogaster as revealed by accumulation of the nuclear engrailed protein. Cell 43: 59-69.

Fjose, A., W. McGinnis, and W. Gehring. 1985. Isolation of a homeobox-containing gene from the engrailed region of Drosophila and the spatial distribution of its transcript. $\mathrm{Na}$ ture 313: 284-289.

Garcia-Bellido, A., P. Ripoll, and G. Morata. 1973. Developmental compartmentalization of the wing disc of Drosophila. Nat. New Biol. 245: 251-253.

Hama, C., Z. Ali, and T. Kornberg. 1990. Region-specific recombination and expression are directed by portions of the Drosophila engrailed promoter. Genes Dev. 4 (in press).

Hochman, B. 1971. Analysis of chromosome 4 in Drosophila melanogaster. II. Ethyl methanesulfonate induced lethals. Genetics 67: 235-252.

1973. Analysis of a whole chromosome in Drosophila. Cold Spring Harbor Symp. Quant. Biol. 38: 581-589.

. 1976. The fourth chromosome of Drosophila melanogaster. In The genetics and biology of Drosophila (ed., M. Ashburner and Novitski), pp. 903-928. Academic Press, New York.

Hoey, T. and M. Levine. 1988. Divergent homeobox proteins recognize similar DNA sequences in Drosophila. Nature 332: $858-861$

Jowett, T. 1986. Preparation of nucleic acids. In Drosophila: $A$ practical approach (ed. D.B. Roberts), pp. 275-286. IRL Press, Oxford

Jurgens, G., E. Wieschaus, C. Nüsslein-Volhard, and H. Kluding. 1984. Mutations affecting the pattern of the larval cuticle in Drosophila melanogaster. II. Zygotic loci on the third chromosome. Wilhelm Roux's Arch. Dev. Biol. 193: 283-295.

Karr, T.L., Z. Ali, B. Drees, and T. Komberg. 1985. The engrailed locus of Drosophila melanogaster provides an essential zygotic function in precellular embryos. Cell 43: 591601.

Karr, T.L., M.J. Weir, Z. Ali, and T. Kornberg. 1989. Patterns of engrailed protein in early Drosophila embryos. Development 105: 605-612.

Kornberg, T. 1981a. engrailed: A gene controlling compartment and segment formation in Drosophila. Proc. Natl. Acad. Sci. 78: $1095-1099$.

1981b. Compartments in the abdomen of Drosophila and the role of the engrailed locus. Dev. Biol. 86:363-372.

Komberg, T., I. Siden, P. O'Farrell, and M. Simon. 1985. The engrailed locus of Drosophila: In situ localization of transcripts reveals compartment-specific expression. Cell 40: $45-53$.

Kuner, I., M. Nakanishi, Z. Ali, B. Drees, E. Gustavson, J. Theis, L. Kauvar, T. Kornberg, and P. O'Farrell. 1985. Molecular cloning of engrailed: A gene involved in the development of pattern in Drosophila melanogaster. Cell 42: 309-316.

Lawrence, P. and G. Morata. 1976. Compartments in the wing 
of Drosophila: A study of the engrailed gene. Dev. Biol. 50: $321-337$.

Lawrence, P. and G. Struhl. 1982. Further studies of the engrailed phenotype in Drosophila. EMBO J. 1: 827-833.

Lindsley, D.L. and E.H. Grell. 1968. Genetic variations of Drosophila melanogaster. Carnegie Inst. Wash. Publ. 627.

Maniatis, T., E.F. Fritsch, and J. Sambrook. 1982. Molecular Cloning: A laboratory manual. Cold Spring Harbor Press, Cold Spring Harbor, New York.

Nüsslein-Volhard, C. and E. Wieschaus. 1980. Mutations affecting segment number and polarity in Drosophila. Nature 287: 795-801.

Nüsslein-Volhard, C., E. Wieschaus, and H. Kluding. 1984. Mutations affecting the pattern of the larval cuticle in Drosophila melanogaster. I. Zygotic loci on the second chromosome. Wilhelm Roux's Arch. Dev. Biol. 193: 267-282.

Orenic, T., J. Chidsey, and R. Holmgren. 1987. Cell and cubitus interruptus Dominant: Two segment polarity genes on the fourth chromosome. Dev. Biol. 124: 50-56.

Orenic, T., D. Slusarski, K. Kroll, and R. Holmgren. 1990. Cloning and segment polarity gene cubitus interruptus of Drosophila. Genes Dev. 4: 1058-1073.

Perrimon, N. and A.P. Mahowald. 1987. Multiple functions of segment polarity genes in Drosophila. Dev. Biol. 119: 175189.

Poole, S.J., L.M. Kauvar, B. Drees, and T. Kornberg. 1985. The engrailed locus of Drosophila: Structural analysis of an embryonic transcript. Cell 40: 37-43.

Wilson, C., R.K. Pearson, H.J. Bellen, C.J. O'Kane, U. Grossniklaus, and W.J. Gehring. 1989. P-element-mediated enhancer detection: An efficient method for isolating and characterizing developmentally regulated genes in Drosophila. Genes Dev. 3: 1301-1313. 


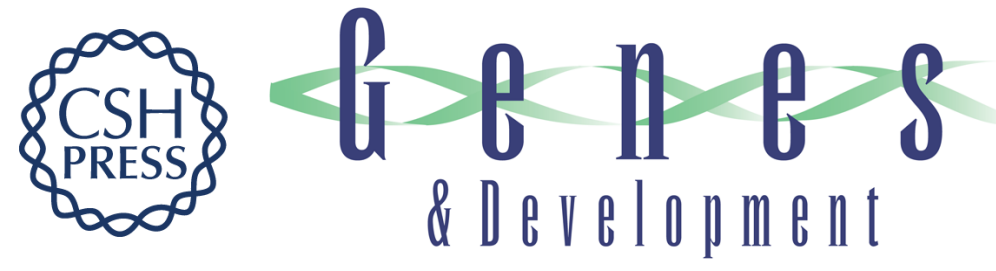

\section{Repression of ci-D in posterior compartments of Drosophila by engrailed.}

$S$ Eaton and T B Kornberg

Genes Dev. 1990, 4:

Access the most recent version at doi:10.1101/gad.4.6.1068

References This article cites 27 articles, 6 of which can be accessed free at:

http://genesdev.cshlp.org/content/4/6/1068.full.html\#ref-list-1

License

Email Alerting

Service

Receive free email alerts when new articles cite this article - sign up in the box at the top right corner of the article or click here.

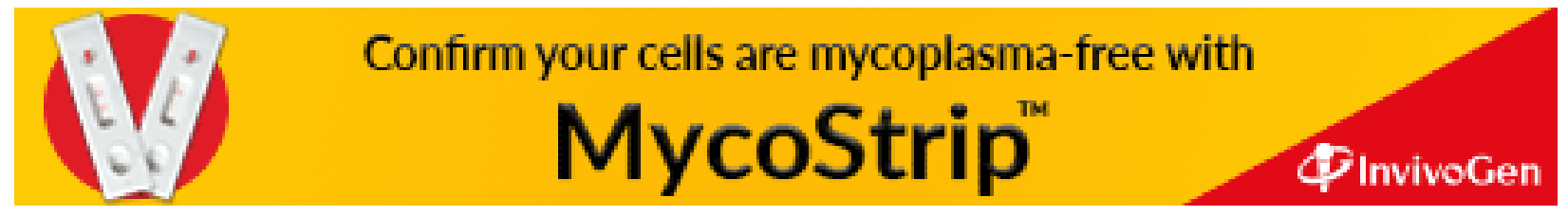

